\title{
THE KINETICS OF COMPETITIVE CONSECUTIVE SECOND- ORDER REACTIONS: THE TWO-STEP HYDROLYSIS OF DIMETHOXO(TETRA-p-TOLYLPORPHYRINATO)TIN(IV)
}

\author{
CHING-CHU TSAI, YAO-JUNG CHEN and JYH-HORUNG CHEN* \\ Department of Chemistry, National Chunghsing University, Taichung, \\ Taiwan 40227, R.O.C.
}

and

\section{LIAN-PIN HWANG}

\begin{abstract}
Department of Chemistry, National Taiwan University and Institute of Atomic
\end{abstract} and Molecular Science, Academia Sinica, Taipei, Taiwan, R.O.C.

(Received 4 November 1991 ; accepted 31 January 1992)

\begin{abstract}
The hydrolysis of a new compound, dimethoxo(tetra-p-tolylporphyrinato)tin (IV), Sn(tptp)(OMe) $)_{2}$, was studied by NMR spectroscopy. The use of a limited amount of water in $\mathrm{CDCl}_{3}$ allowed the hydrolysis intermediate, hydroxomethoxo(tetra-p-tolylporphyrinato)tin(IV), to be identified. The results show that the hydrolysis is a two-step competitive consecutive second-order reaction, with an absolute rate constant of the first step $k_{1}=(6.63 \pm 0.66) \times 10^{-3} \mathrm{~s}^{-1} \mathrm{M}^{-1}$ and that of the second step $k_{2}=(3.55 \pm 0.35) \times 10^{-3}$ $\mathrm{s}^{-1} \mathrm{M}^{-1}$ at $28 \pm 2^{\circ} \mathrm{C}$.
\end{abstract}

${ }^{1} \mathrm{H}$ NMR spectroscopy provides a convenient means of identifying and quantifying reaction intermediates. Previous workers have reported the difficulty in detecting dimethoxo(tetraphenylporphyrinato)tin(IV), Sn(tpp)(OMe) ${ }_{2}(\mathrm{tpp}=5,10,15$, 20-tetraphenylporphyrinato), by ${ }^{1} \mathrm{H}$ NMR spectroscopy due to its rapid hydrolysis to dihydroxo (tetraphenylporphyrinato)tin(IV), Sn (tpp)(OMe) ${ }_{2}$, unless $\mathrm{CDCl}_{3}$ is specially dried. ${ }^{1,2}$ Recently, we reported the two-step hydrolysis of dimethoxo (tetraphenylporphyrinato)tin(IV), Sn(tpp)(OMe) ${ }_{2}$, by ${ }^{1} \mathrm{H}$ NMR spectroscopy. ${ }^{3}$ In the previous paper, ${ }^{3}$ the absolute values of two consecutive rate constants $k_{1}$ and $k_{2}$ could not be determined since the precise concentration of water was not measured. However, an analysis of data led to an estimate of 2.3 for the ratio $k_{1} / k_{2}$. The new compound described in this paper, dimethoxo (tetra-p-tolylporphyrinato)tin(IV), $\mathrm{Sn}(\mathrm{tptp})(\mathrm{OMe})_{2}$, was synthesized and used in the hydrolysis investigation. With the aid of ${ }^{119} \mathrm{Sn}$ and ${ }^{117} \mathrm{Sn}$ couplings,

*Author to whom correspondence should be addressed. the stoichiometry of the species $\mathrm{Sn}(\mathrm{tptp})(\mathrm{OMe})_{2}$ (B), hydroxomethoxo(tetra-p-tolylporphyrinato)tin(IV), $\mathrm{Sn}(\mathrm{tptp})(\mathrm{OMe})(\mathrm{OH}) \quad(\mathrm{C})$, and dihydroxo(tetra$p$-tolylporphyrinato)tin(IV), $\quad \mathrm{Sn}(\operatorname{tptp})(\mathrm{OH})_{2} \quad$ (D) (shown in Fig. 1), was determined from the relative intensities of the ${ }^{\prime} \mathrm{H}$ signals of the hydroxy and methoxy groups. The results indicate that there is a two-step competitive consecutive second-order process involved in the hydrolysis of $\mathrm{Sn}(\mathrm{tptp})$ $(\mathrm{OMe})_{2}$ to $\mathrm{Sn}(\mathrm{tptp})(\mathrm{OH})_{2}$. With the aid of known water concentration determined by proton NMR intensity, the graphical-integration time-variable transformtion method was used to evaluate the absolute values for both rate constants.

\section{EXPERIMENTAL}

\section{Preparation of $\mathrm{Sn}(\mathrm{tptp})(\mathrm{OMe})_{2}$}

$\mathrm{Sn}(\mathrm{tptp})(\mathrm{OMe})_{2}$ was prepared by substituting meso-tetraphenylporphyrinato, tpp, with mesotetra-( $p$-tolyl)porphyrin, tptp, in the preparation of $\mathrm{Sn}(\mathrm{tptp})(\mathrm{OMe})_{2}$ as described elsewhere. ${ }^{1,3,4}$ 


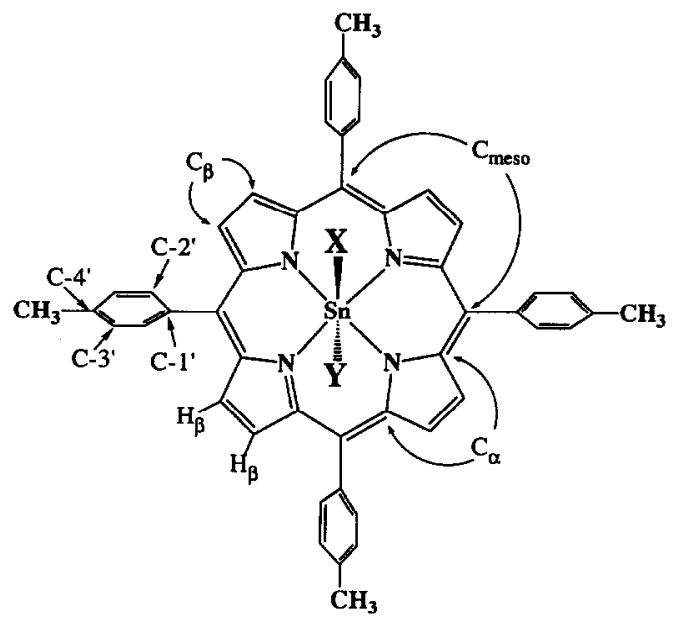

\begin{tabular}{lll} 
& \multicolumn{1}{c}{$\mathbf{X}$} & $\mathbf{Y}$ \\
\cline { 2 - 3 } (B) & $\mathrm{OMe}$ & $\mathrm{OMe}$ \\
(C) & $\mathrm{OMe}$ & $\mathrm{OH}$ \\
(D) & $\mathrm{OH}$ & $\mathrm{OH}$
\end{tabular}

Fig. 1. Structure of Sn(tptp)XY complexes.

\section{NMR sample preparation}

Deuterated chloroform (99.8\% from Aldrich) was dried with $\mathrm{CaCl}_{2}$. The trace amount of residual water in $\mathrm{CDCl}_{3}$ was quantified by an NMR method after the sample solution was prepared. The sample was prepared by dissolving $\mathrm{Sn}(\mathrm{tptp})(\mathrm{OMe})_{2}$ in $\mathrm{CDCl}_{3}$ to give a concentration of $2.53 \times 10^{-2} \mathrm{M}$. Immediately after the freshly prepared solution was poured into a $5 \mathrm{~mm}$ NMR tube, the tube was sealed with a plastic cap, wrapped with parafilm and measured at $28 \pm 2^{\circ} \mathrm{C}$.

\section{NMR spectra}

${ }^{1} \mathrm{H}$ and ${ }^{13} \mathrm{C}$ NMR spectra were recorded at 300 and $75.46 \mathrm{MHz}$, respectively, on a Varian VXR300 spectrometer.

\section{RESULTS AND DISCUSSION}

The hydrolysis of $\mathrm{Sn}(\mathrm{tptp})(\mathrm{OMe})_{2}$ may be expressed as a two-step competitive consecutive secondorder reaction. Let $\mathrm{A}=\mathrm{H}_{2} \mathrm{O}, \mathrm{B}=\mathrm{Sn}(\mathrm{tptp})(\mathrm{OMe})_{2}$, $\mathrm{C}=\mathrm{Sn}(\operatorname{tptp})(\mathrm{OMe})(\mathrm{OH}), \mathrm{D}=\mathrm{Sn}(\mathrm{tptp})(\mathrm{OH})_{2}$ and $\mathrm{E}=\mathrm{MeOH}$. The chemical equations for the hydrolysis of $\mathbf{B}$ are

$$
\begin{aligned}
& \mathrm{A}+\mathrm{B} \stackrel{k_{1}}{\longrightarrow} \mathrm{C}+\mathrm{E}(\operatorname{step} 1) \\
& \mathrm{A}+\mathrm{C} \stackrel{k_{2}}{\longrightarrow} \mathrm{D}+\mathrm{E}(\operatorname{step} 2)
\end{aligned}
$$

where $k_{1}$ and $k_{2}$ are the rate constants for steps 1 and 2, respectively.

For eqs (1) and (2), the pertinent rate equations are

$$
\begin{gathered}
\frac{\mathrm{d}[\mathrm{B}]}{\mathrm{d} t}=-k_{1}[\mathrm{~A}][\mathrm{B}] \\
\frac{\mathrm{d}[\mathrm{C}]}{\mathrm{d} t}=k_{1}[\mathrm{~A}][\mathrm{B}]-k_{2}[\mathrm{~A}][\mathrm{C}] \\
\frac{\mathrm{d}[\mathrm{D}]}{\mathrm{d} t}=k_{2}[\mathrm{~A}][\mathrm{C}] .
\end{gathered}
$$

From the principle of material balance, they read

$$
[\mathrm{B}]+[\mathrm{C}]+[\mathrm{D}]=[\mathrm{B}]_{0}+[\mathrm{C}]_{0}+[\mathrm{D}]_{0}
$$

and

$$
\begin{aligned}
{[\mathrm{A}]+[\mathrm{B}]+[\mathrm{C}] } & +[\mathrm{D}]+[\mathrm{E}] \\
& =[\mathrm{A}]_{0}+[\mathrm{B}]_{0}+[\mathrm{C}]_{0}+[\mathrm{D}]_{0}+[\mathrm{E}]_{0}
\end{aligned}
$$

where the subscripts 0 represent the initial concentrations of the respective chemical species.

It is apparent that eqs (3)-(5) may be readily converted to equations of first-order type by introduction of the parameter ${ }^{5-10} \theta=\int_{0}^{t}\left[\mathrm{H}_{2} \mathrm{O}\right] \mathrm{d} t$. On integration, we obtain

$$
\begin{gathered}
{[\mathrm{B}]=[\mathrm{B}]_{0} \mathrm{e}^{-k_{1} \theta}} \\
{[\mathrm{C}]=[\mathrm{C}]_{0} \mathrm{e}^{-k_{2} \theta}+\frac{k_{1}}{k_{2}-k_{1}}[\mathrm{~B}]_{0}\left(\mathrm{e}^{-k_{1} \theta}-\mathrm{e}^{-k_{2} \theta}\right)} \\
{[\mathrm{D}]=[\mathrm{D}]_{0}+[\mathrm{C}]_{0}\left(1-\mathrm{e}^{-k_{2} \theta}\right)} \\
+[\mathrm{B}]_{0}\left(1-\frac{k_{2}}{k_{2}-k_{1}} \mathrm{e}^{-k_{1} \theta}+\frac{k_{1}}{k_{2}-k_{1}} \mathrm{e}^{-k_{2} \theta}\right)
\end{gathered}
$$

The relationship between $\theta$ and $t$ is readily established by plotting $\left[\mathrm{H}_{2} \mathrm{O}\right]$ against $t$ and integrating graphically. The data giving $\left[\mathrm{H}_{2} \mathrm{O}\right]$ as a function of $t$ are then converted to the $\theta$ basis and subsequently handled as a first-order process.

NMR spectra of $\mathrm{Sn}(\mathrm{tptp})(\mathrm{OMe})_{2}$ at various stages of hydrolysis are displayed in Figs 2 and 3. The proton NMR spectrum from the hydrolysis of $\mathrm{Sn}(\mathrm{tptp})(\mathrm{OMe})_{2}$ at reaction time $t=20 \mathrm{~min}$ is shown in Fig. 2. The peaks corresponding to the three compounds B-D at various times are shown in Fig. 3. Figure 3a is the NMR spectrum obtained 3 min after dissolution; it is dominated by the $\mathrm{Sn}(\mathrm{tptp})(\mathrm{OMe})_{2}$ resonance $\mathrm{j}$, with a smaller resonance $\mathrm{l}^{\prime}$ for $\mathrm{Sn}(\mathrm{tptp})(\mathrm{OMe})(\mathrm{OH})$ and an almost negligible $\mathrm{Sn}(\mathrm{tptp})(\mathrm{OH})_{2}$ resonance $\mathrm{m}$. Figure $3 b-$ $\mathrm{d}$ shows increasing production of $\mathrm{Sn}(\mathrm{tptp})(\mathrm{O}-$ $\mathrm{Me})(\mathrm{OH})$ and $\mathrm{Sn}(\mathrm{tptp})(\mathrm{OH})_{2}$ with reaction time $t$.

The time-dependent concentrations of the five species $\mathrm{Sn}(\mathrm{tptp})(\mathrm{OMe})_{2}, \mathrm{Sn}(\mathrm{tptp})(\mathrm{OMe})(\mathrm{OH}), \mathrm{Sn}$ (tptp) $(\mathrm{OH})_{2}, \mathrm{MeOH}$ and $\mathrm{H}_{2} \mathrm{O}$ are shown in Fig. 4. 


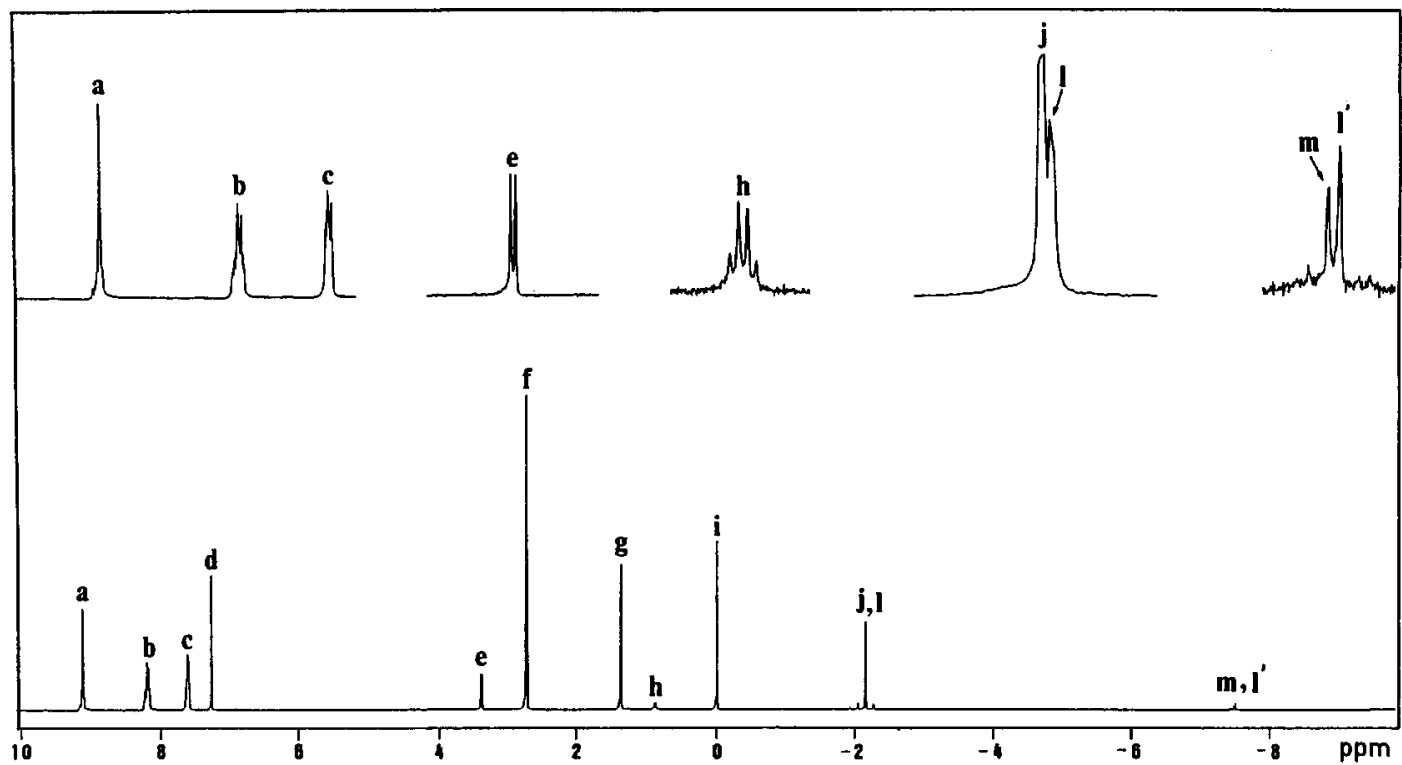

Fig. 2. NMR spectrum for $\mathrm{Sn}(\mathrm{tptp})(\mathrm{OMe})_{2}$ hydrolysis after a rcaction time of $20 \mathrm{~min}$. The spectral resonances used to measure the concentrations of compounds $\mathrm{B}-\mathrm{D}, \mathrm{MeOH}$ and $\mathrm{H}_{2} \mathrm{O}$ are shown. The proton assignments are: (a) $\mathrm{H}_{\beta}$ (pyrrole); (b) phenyl $\mathrm{H}$ (ortho); (c) phenyl $\mathrm{H}$ (meta); (d) $\mathrm{CHCl}_{3}$; (e) methyl group of methanol; (f) $p-\mathrm{CH}_{3}$; (g) hydroxy group of water; (h) methanol OH group; (i) tetramethyl silane ; (j) methoxy group of $\mathrm{Sn}(\operatorname{tptp})(\mathrm{OMe})_{2} ;(1)$ methoxy group of $\mathrm{Sn}(\mathrm{tptp})(\mathrm{OMe})(\mathrm{OH})$;

$\left(1^{\prime}\right)$ hydroxy group of $\operatorname{Sn}(\operatorname{tptp})(\mathrm{OMe})(\mathrm{OH}) ;(\mathrm{m})$ hydroxy group of $\operatorname{Sn}(\mathrm{tptp})(\mathrm{OH})_{2}$.

The initial build-up and subsequent decay of $\mathrm{Sn}(\mathrm{tptp})(\mathrm{OMe})(\mathrm{OH})$ are clearly evident for $k_{2}<k_{1}$. Further experiments indicate that more than $95 \%$ of the initial concentration of $\operatorname{Sn}(t p t p)(\mathrm{OMe})_{2}$ is consumed within $3 \mathrm{~h}$. Thus the reactions with water are essentially irreversible. The initial water concentration was quantified by the NMR integration method with respect to the known $\operatorname{Sn}(\operatorname{tptp})(\mathrm{OMc})_{2}$ concentration of $2.53 \times 10^{-2} \mathrm{M}$. As the reaction proceeds, the increase of methanol concentration and the decrease of water concentration as expressed in eqs (1) and (2) were monitored by integration of the peaks $e$ and $g$ shown in Fig. 2 and comparison with the known $\mathrm{Sn}(\mathrm{tptp})(\mathrm{OMe})_{2}$ concentration at peak $\mathrm{j}$. The result is also shown in Fig. 4. The value of the new time variable, $\theta$, at any time was

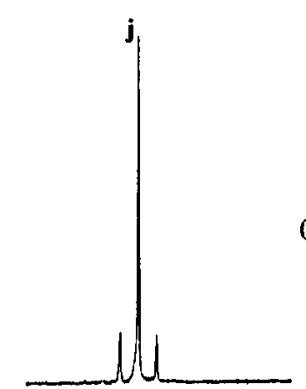

(a) $\mathbf{t}=\mathbf{3} \min$

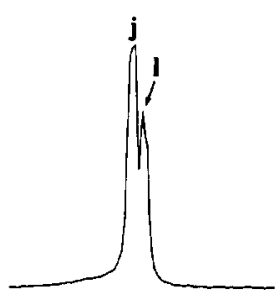

(b) $t=20$ min
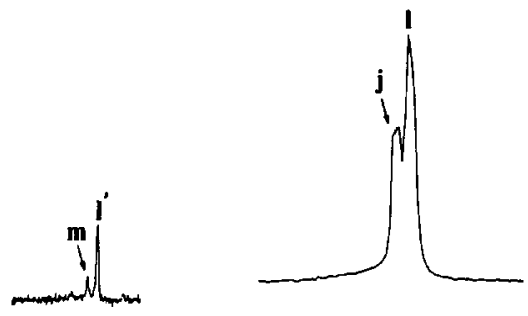

(c) $t=50 \mathrm{~min}$

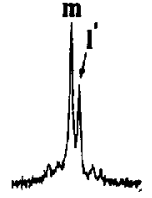

Fig. 3. NMR spectra for $\mathrm{Sn}(\mathrm{tptp})(\mathrm{OMe})_{2}$ hydrolysis after reaction times of $3 \mathrm{~min}$ (a), $20 \mathrm{~min}$ (b), 50 $\min (\mathrm{c})$ and $90 \mathrm{~min}(\mathrm{~d})$. 


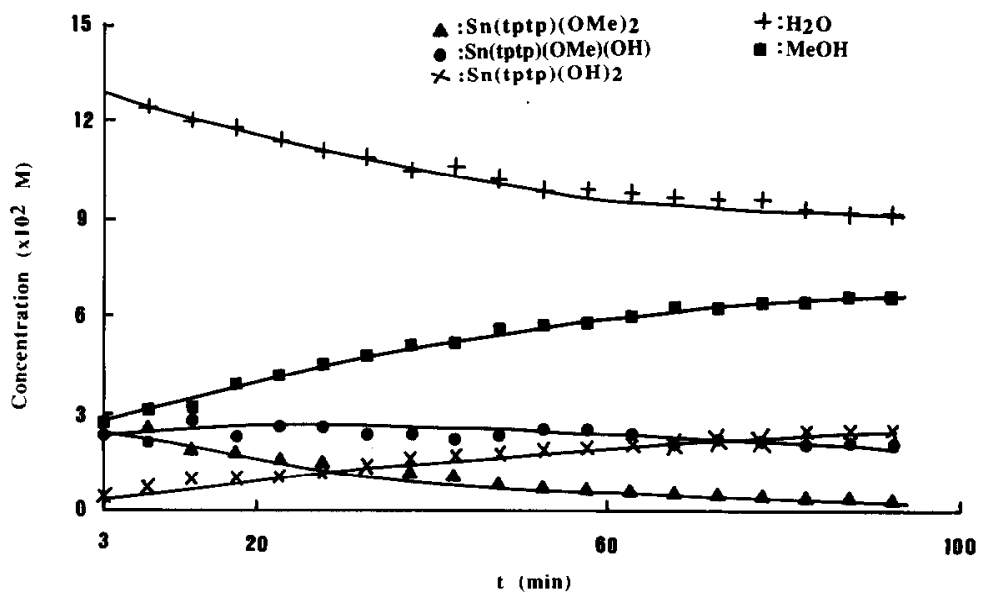

Fig. 4. A plot showing the concentration of compounds A-E with respect to reaction time. The concentrations of these five compounds are obtained by normalizing with eq. (7). The solid curves are graphed to guide the eye.

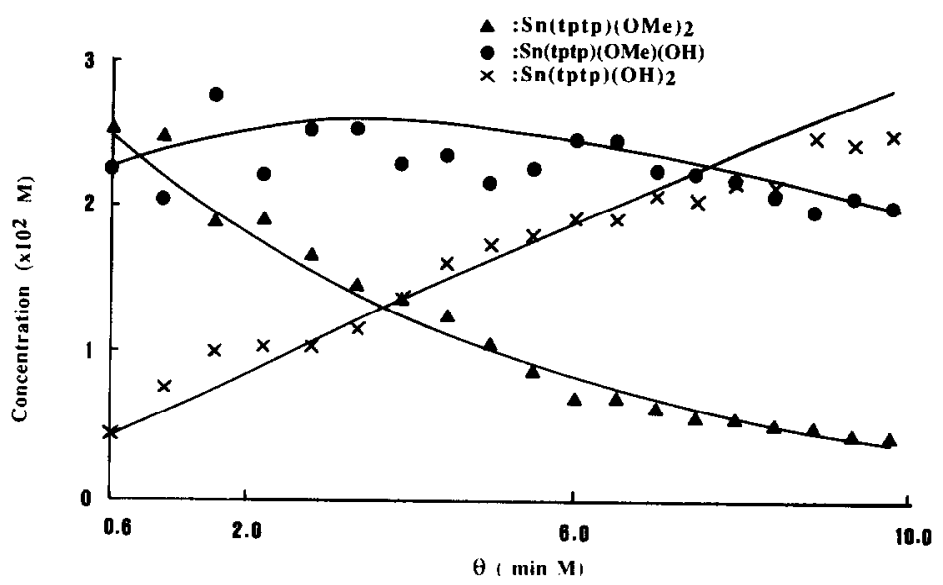

Fig. 5. A plot showing the concentration of compounds B-D with respect to $\theta$ (see Fig. 4) at $28 \pm 2^{\circ} \mathrm{C}$. The solid curves were obtained by computer-fitting with eqs $(8)-(10)$. This yields $k_{1}=(6.63 \pm 0.66) \times$ $10^{-3} \mathrm{~s}^{-1} \mathrm{M}^{-1} ; k_{2}=(3.55 \pm 0.35) \times 10^{-3} \mathrm{~s}^{-1} \mathrm{M}^{-1} ; K=0.54 \pm 0.11$.

Table 1. 'H NMR chemical shifts ( $\delta$ in ppm) ${ }^{a}$ and ${ }^{1} \mathrm{H}-{ }^{117,119} \mathrm{Sn}$ coupling constants $(J$ in $\mathrm{Hz}$ ) for compounds B-D

\begin{tabular}{|c|c|c|c|c|c|c|c|c|c|}
\hline \multirow[b]{2}{*}{ Compound } & \multicolumn{2}{|c|}{ Pyrrole H } & \multirow{2}{*}{$\begin{array}{c}\text { Phenyl H } \\
\text { (ortho) }\end{array}$} & \multirow{2}{*}{$\begin{array}{l}\text { Phenyl H } \\
\text { (meta) }\end{array}$} & \multirow[b]{2}{*}{$p-\mathrm{Me}$} & \multicolumn{2}{|c|}{$\mathrm{Sn}-\mathrm{OH}$} & \multicolumn{2}{|c|}{$\mathrm{Sn}-\mathrm{OMe}$} \\
\hline & $\delta$ & $J(\mathrm{Sn}-\mathrm{H})$ & & & & $\delta$ & $J(\mathrm{Sn}-\mathrm{H})$ & $\delta$ & $J(\mathbf{S n}-\mathrm{H})$ \\
\hline B & 9.12 & - & $8.19\left(\mathrm{~d}^{\mathrm{d}}\right)$ & 7.60 (d) & 2.73 & - & - & -2.16 & $\begin{array}{l}70.0\left({ }^{119} \mathrm{Sn}\right) \\
66.8\left({ }^{117} \mathrm{Sn}\right)\end{array}$ \\
\hline $\mathrm{C}$ & 9.13 & - & 8.21 & 7.61 & 2.73 & -7.50 & $\begin{array}{l}35.6\left({ }^{119} \mathrm{Sn}\right) \\
34.0\left({ }^{117} \mathrm{Sn}\right)\end{array}$ & -2.15 & $\begin{array}{l}71.4\left({ }^{119} \mathrm{Sn}\right) \\
68.2\left({ }^{117} \mathrm{Sn}\right)\end{array}$ \\
\hline D & 9.15 & 10.6 & $8.22(d)$ & 7.62 (d) & 2.73 & -7.48 & $\begin{array}{l}37.0\left(\left(^{119} \mathrm{Sn}\right)\right. \\
35.6\left({ }^{1{ }^{17}} \mathrm{Sn}\right)\end{array}$ & - & - \\
\hline $\mathrm{D}^{b}$ & 9.13 & 12.2 & 8.21 & 7.62 (d) & 2.73 & -7.49 & 36.1 & - & - \\
\hline $\mathrm{D}^{c}$ & 9.14 & 10.3 & 8.21 & 7.61 & $\ldots$ & $-7.46(\mathrm{br})$ & & - & - \\
\hline
\end{tabular}

${ }^{a}$ Chemical shifts in ppm relative to TMS.

${ }^{h}$ From ref. 11.

${ }^{c}$ From ref. 2.

${ }^{d} \mathrm{~d}=$ doublet. 
Table $2 .{ }^{13} \mathrm{C}$ NMR chemical shifts ( $\delta$ in ppm) ${ }^{a}$ for compounds B-D

\begin{tabular}{cccccccccc}
\hline Compound & C- $\alpha$ & C- $\beta$ & C-meso & C-1 $^{\prime}$ & C-2 & C-3 & C-4 & C $(p-\mathrm{Me})^{b}$ & C(OMe) \\
\hline B & 147.3 & 132.3 & 121.6 & 138.6 & 135.1 & 127.6 & 137.8 & 21.5 & 44.6 \\
C & 147.0 & 132.4 & 121.4 & 138.6 & 135.0 & 127.7 & 137.9 & 21.5 & 44.6 \\
D & 146.7 & 132.6 & 121.2 & 138.4 & 135.0 & 127.7 & 137.9 & 21.5 & - \\
\hline
\end{tabular}

${ }^{a}$ Chemical shifts relative to the centre line of the $\mathrm{CDCl}_{3}$ triplet at $77.0 \mathrm{ppm}$.

${ }^{b} p$-Me is the methyl group at the para position.

determined by graphical integration of $\int_{0}^{t}\left[\mathrm{H}_{2} \mathrm{O}\right] \mathrm{d} t$ and thereby the relationship between $\left[\mathrm{H}_{2} \mathrm{O}\right]$ and $\theta$ established. The $t$-dependence for compounds B-D shown in Fig. 4 was then transformed to $\theta$-dependence as shown in Fig. 5. The solid curves were computer-fitted with eqs $(8)-(10)$ at $28 \pm 2^{\circ} \mathrm{C}$. They give $k_{1}=(6.63 \pm 0.66) \times 10^{-3} \mathrm{~s}^{-1} \mathrm{M}^{-1}, k_{2}=(3.55$ $\pm 0.35) \times 10^{-3} \mathrm{~s}^{-1} \mathrm{M}^{-1}$ and $K=k_{2} / k_{1}=0.54 \pm$ 0.11 . This $K$ value is comparable with $K=0.43$ obtained from the hydrolysis of a similar compound, $\mathrm{Sn}(\mathrm{tpp})(\mathrm{OMe})_{2}{ }^{3}$

The ${ }^{l} \mathrm{H}$ NMR data for compounds B-D are displayed in Table 1, together with relevant literature data. ${ }^{2,11}{ }^{13} \mathrm{C}$ chemical shifts for compounds B-D are given in Table $2 .{ }^{13} \mathrm{C}$ shifts were assigned with the aid of published data of a similar compound. ${ }^{3}$

In this work a controlled trace amount of water has been involved in the study of the hydrolysis of $\mathrm{Sn}(\mathrm{tptp})(\mathrm{OMe})_{2}$ to $\mathrm{Sn}(\mathrm{tptp})(\mathrm{OH})_{2}$. A two-step competitive consecutive second-order process with $\mathrm{Sn}(\mathrm{tptp})(\mathrm{OMe})(\mathrm{OH})$ as an intermediate has been found. The exact solution for the rate constant of the first step is $k_{1}=(6.63 \pm 0.66) \times 10^{-3} \mathrm{~s}^{-1} \mathrm{M}^{-1}$ and that of the second step is $k_{2}=(3.55 \pm 0.35)$ $\times 10^{-3} \mathrm{~s}^{-1} \mathrm{M}^{-1}$ at $28 \pm 2^{\circ} \mathrm{C}$. The graphical-integration time-variable transformation method developed in this work may be applied to the study of the kinetics of general competitive consecutive secondorder reactions.

Acknowledgement-Financial support from the National Research Council of the R.O.C. under Grant NSC 800208-M-005-13 is gratefully acknowledged.

\section{REFERENCES}

1. D. P. Arnold, J. Chem. Educ. 1988, 65, 1111.

2. D. P. Arnold, Polyhedron 1988, 7, 2225.

3. H. J. Lin, J. H. Chen and L. P. Hwang, Aust. J. Chem. 1991, 44, 747.

4. R. J. Abraham, G. E. Hawkes, M. F. Hudson and K. M. Smith, J. Chem. Soc., Perkin II 1975, 204.

5. W. G. McMillan, J. Am. Chem. Soc. 1957, 79, 4838.

6. D. French, J. Am. Chem. Soc. 1950, 72, 4806.

7. A. A. Frost and W. C. Schwemer, J. Am. Chem. Soc. 1952, 74, 1268.

8. S. Wideqvist, Acta Chem. Scand. 1950, 4, 1216.

9. S. Wideqvist, Acta Chem. Scand. 1962, 16, 1119.

10. J. W. Moore and R. G. Pearson, Kinetics and Mechanism, 3rd edn, pp. 300-304. John Wiley, New York (1981).

11. K. M. Kadish, Q. Y. Y. Xu and G. B. Maiya, J. Chem. Soc., Dalton Trans. 1989, 1531. 